\title{
Servindo a dois senhores: as políticas sociais no governo Lula
}

\author{
Rosa Maria Marques \\ Política da Pontifícia Universidade Católica de São Paulo (PUCSP)
}

\author{
Áquilas Mendes \\ Pontifícia Universidade Católica de São Paulo (PUCSP) \\ Fundação Armando Álvares Penteado (FAAP/SP)
}

Servindo a dois senhores: as políticas sociais no governo Lula

Resumo: Este artigo faz um balanço das principais iniciativas do governo Lula em matéria de políticas sociais. É foco de sua atenção a reforma da previdência dos servidores; a postura quanto ao orçamento do Sistema Único de Saúde; a posição com relação aos recursos da Seguridade Social; o significado e a abrangência do programa de transferência de renda Bolsa Família e a evolução da renda de ocupação e do salário mínimo. Sua conclusão é que essas iniciativas estão de acordo com a política econômica, que privilegia o capital financeiro. Destaca-se, contudo, que o Bolsa Família tenha beneficiado parcela antes excluída da atenção de governos, resgatando-a da situação de miséria absoluta, e que o salário mínimo real tenha sofrido aumento substantivo, embora longe do prometido na campanha eleitoral. O artigo, ainda, discute as limitações do Programa Bolsa Família e discute as razões desse não se constituir um direito.

Palavras-chave: governo Lula, políticas sociais, Bolsa Família.

\section{Serving Two Masters: Social Policies in the Lula Government}

Abstract: This article reviews the principal social policy initiatives of the Lula government. It focuses on social security reform for government employees; the government position concerning the Single Health Care System budget and Social Security Resources; the significance and scope of the Family Grant income transfer program and changes in labor income and the minimum wage. The article concludes that these initiatives are in keeping with the government's economic policy, which benefits financial capital. It highlights, however, that the Family Grant program has benefited a portion of the population previously excluded from government attention, removing them from absolute poverty, and that the real minimum wage has undergone a substantial increase, although it is far from that promised in Lula's 2002 campaign. The article also discusses the limitations of the Family Grant Program and the reasons that it has not been established as a right.

Key words: Lula government, social policies, Family Grant. 
Ninguém pode servir a dois senhores; porque ou há de aborrecer-se de um

e amar ao outro,

ou se devotará a um e desprezará ao outro.

Não podeis servir a Deus e às riquezas. Sermão da Montanha, Mateus, 6: 24

\section{Introdução}

Uma leitura apressada do que foi o primeiro governo Lula (2003-2006) nos levaria a dizer que é possível servir a dois senhores, mesmo se assim estivéssemos contrariando a Bíblia. Isso porque, se de um lado sua política econômica favoreceu largamente os interesses do capital financeiro nacional e internacional (garantindo elevada rentabilidade mediante a manutenção de elevadas taxas de juros e viabilizando um lucro bancário recorde) e do agribusiness, por outro, implementou uma série de programas e iniciativas, direcionada aos segmentos mais pobres da população brasileira e àqueles até então excluídos de algumas políticas. E na compreensão corrente de seus críticos, à esquerda de suas posições, essa possibilidade não seria possível, pois haveria uma total oposição entre essas duas 'orientações': os programas e as iniciativas do governo são vistos, no máximo, como meramente assistenciais, passíveis de críticas de toda ordem.

Mas até que ponto os programas e iniciativas, implementados pelo governo Lula podem ser considerados meramente assistenciais ou compensatórios, como dizem os economistas não acostumados com o objeto da política social? Esses programas e políticas alteraram ou não as condições de existência de seus beneficiados, melhorando sua renda e possibilitando o acesso a determinados coberturas e/ou serviços? E ainda, até que ponto pode-se afirmar que uma melhora na situação dos mais pobres e dos excluídos não é possível num quadro de favorecimento do grande capital? Estas são as perguntas que se colocam quando se faz um balanço do que foi o primeiro governo Lula em matéria de políticas sociais. Respondê-las é uma obrigação não só daqueles que atuam na área social, mas também daqueles que estão preocupados em construir um novo país, que rompa com seu passado histórico de miséria e desigualdade.

$\mathrm{Na}$ tentativa de avançar nessa discussão, este artigo procura fazer um balanço do que foi o governo Lula em matéria de política social. Para isso adotouse uma definição de política social um pouco mais abrangente que a usual na literatura. Não se trata nem do entendimento restrito, que vigorou no texto constitucional e deu origem à seguridade social, nem de seu sentido mais amplo, que contempla a educação e a moradia, tal como é o entendimento em alguns países europeus (MARQUES, 1997) um e outro, contudo, emanando do reconhecimento de direitos, sejam eles concedidos por mérito ou derivados da cidadania. A definição aqui adotada compreende tanto a proteção garantida por direito como o conjunto de ações governamentais voltados para diminuir a pobreza absoluta, a desigualdade de renda e para propiciar a inclusão.

Quanto ao fato de a política econômica do governo Lula ter favorecido o grande capital, em especial o financeiro, não é objetivo deste artigo sua demonstração. Nos quatro primeiros anos de sua gestão, acumularam-se inúmeros estudos e artigos que detalham esse favorecimento. Entre as diversas contribuições, destacamos Oliveira (2003), De Paula (2005), Marques e Nakatani (2006), entre outros. Neste artigo é pressuposto, portanto, que o governo Lula manteve os juros atrelados às metas de inflação (o que provocou sua permanência em níveis extremamente elevados); aprofundou o esforço de geração de superávit primário com vista ao pagamento do serviço da dívida e comandou um crescimento pífio e errático da economia, fundado principalmente nas exportações do agribusiness. Foi nos seus três primeiros de gestão que as cinco maiores instituições bancárias auferiram um lucro de $26 \%$, superior ao ocorrido nos oito anos de seu antecessor.

$\mathrm{O}$ artigo está estruturado em três partes. A primeira aborda a diminuição dos direitos sociais no governo Lula em decorrência da política fiscal restritiva, ancorada na manutenção do superávit primário, com reflexos significativos na previdência social e nos recursos do Sistema Único de Saúde (SUS). São apresentados os limites da reforma previdenciária do governo Lula, bem como os constrangimentos orçamentários para a saúde pública. A segunda parte trata da forma e do conteúdo do programa central de combate à pobreza do governo Lula: o Bolsa Família. Discute-se também a fraca evolução do rendimento dos ocupados, não acompanhando a melhora do salário mínimo, nesse governo. Aúltima parte aponta uma breve conclusão para o fato de que não há contradição entre uma política econômica do governo Lula que privilegia o grande capital financeiro e a implementação de programa de combate à pobreza, voltado às classes mais pobres da população, como é o caso do Bolsa Família.

\section{Reduzindo direitos em nome do superávit fiscal}

\subsection{A contra-reforma previdenciária}

Para o grande público, a maior surpresa oferecida pelo governo Lula em matéria de Seguridade Social talvez tenha sido seu projeto de contra-reforma da previdência social dos funcionários públicos, encaminhada em abril de 2003 para ser apreciada pelo Congresso Nacional e aprovada em dezembro do 
mesmo ano. Nele o governo retomava os principais pontos que haviam sido derrotados durante a reforma promovida por Fernando Henrique Cardoso (1995-2002), inclusive com o apoio ativo de deputados e senadores do Partido dos Trabalhadores (PT). Lá estavam novamente: o estabelecimento de um teto para a aposentadoria dos servidores, pondo fim ao direito à integralidade; e o início de procedimentos que, se aprofundados, levarão à unificação entre o Regime Geral da Previdência Social (RGPS), dos trabalhadores do mercado formal do setor privado da economia, e o dos funcionários públicos.

Apesar da surpresa, negativa para os servidores, seu programa de governo já apontava elementos que estariam presentes tanto na proposta como em sua exposição de motivos. No item relativo à Reforma da Previdência, a partir do parágrafo 47 do Programa de Governo (2002, p.17-20), diz que:

Um dos maiores desafios políticos e administrativos do futuro governo é o equacionamento da questão previdenciária. Para dar conta desse desafio, é necessário um conjunto de iniciativas de curto, médio e longo prazos, para construir soluções estruturais, capazes de permitir que a presente e as futuras gerações de brasileiros possam estar plenamente conscientes e relativamente tranqüilas quanto aos direitos que poderão usufruir após o término de uma longa dedicação de vida laboral. 'Essa profunda reformulação deve ter como objetivo a criação de um sistema previdenciário básico universal, público, compulsório, para todos os trabalhadores brasileiros, do setor público e privado'. O sistema deve ter caráter contributivo, com benefícios claramente estipulados e o valor do piso e do teto de benefícios de aposentadoria claramente definido (parágrafo 47 , grifo nosso).

Quanto ao terceiro pilar do atual sistema previdenciário brasileiro, a previdência complementar, que pode ser exercida através de fundos de pensão patrocinados por empresas ou instituídos por sindicatos (conforme a Lei Complementar 109), voltada para aqueles trabalhadores que querem renda adicional além da garantida pelos regimes básicos, 'deve ser entendida também como poderoso instrumento de fortalecimento do mercado interno futuro e fonte de poupança de longo prazo para o desenvolvimento do país'. É necessário crescimento e fortalecimento dessa instituição por meio de mecanismos de incentivo (parágrafo 57, grifo nosso).

Nesse trecho fica evidente que a equipe que se preparava para assumir a nação partia do pressuposto da existência de um déficit previdenciário; defendia a não distinção entre trabalhadores do setor privado e funcionários públicos; propunha a constru- ção de um sistema único para trabalhadores do setor privado; sustentava a introdução de teto para a aposentadoria dos servidores; e considerava os fundos de pensão instrumentos para o desenvolvimento de longo prazo. Não havia, portanto, motivos para a surpresa, pois não se pode dizer, com propriedade, que Lula alterou seu programa.

$\mathrm{O}$ que não estava nem de longe previsto, foi a introdução da contribuição para os aposentados, o que contraria o princípio da reciprocidade (necessariamente uma contribuição dá origem a um direito futuro, o que não se aplica para quem já é aposentado), e o método utilizado para o encaminhamento e a aprovação de sua proposta. Afora o fato do PT não ter sido chamado a discutir, tanto a exposição de motivos como a condução da discussão da proposta, o projeto na mídia se fundou no uso de meias-verdades, de preconceitos e mesmo de distorção das informações, o que resultou no isolamento dos funcionários públicos na sociedade brasileira (MARQUES; MENDES, 2004). A introdução de um valor máximo para a aposentadoria dos funcionários públicos foi associada à criação de fundos de pensão, os quais, assim como os fundos de pensão dos trabalhadores do setor privado, podem ser organizados e administrados por sindicatos e pelas centrais sindicais. Até o momento, contudo, eles não foram regulamentados, pois a legislação necessária não foi ainda objeto de discussão e aprovação.

Além disso, um dos maiores significados da introdução do teto é o fato dele implicar o rompimento do contrato estabelecido entre o Estado e os servidores atuais. A integralidade, isto é, a garantia de uma aposentadoria de valor igual ao da ativa, era parte constitutiva das relações de trabalho no setor público brasileiro, o que era combinado ao fato dos proventos serem mais baixos dos que os recebidos pelos trabalhadores do setor privado da economia, para o mesmo nível de qualificação. Ao longo da vida, contudo, a renda recebida pelos dois segmentos tenderia a ser igual, pois quando os trabalhadores do setor privado se aposentam sofrem queda abrupta em sua renda (que é tanto mais acentuada quanto maior for o salário da atividade) e os servidores que, durante a atividade recebem menos, continuariam a receber esse mesmo valor quando aposentados. Em outras palavras, o pacto estabelecido entre o Estado brasileiro e seus funcionários era o de garantir uma renda perpétua, embora mais baixa que a paga pelo mercado para o mesmo nível de qualificação. Por meio desse mecanismo, o servidor estava afastado da incerteza em relação a sua renda futura, gerando uma relação consumo/poupança diferente daquela do trabalhador assalariado do setor privado da economia. Isso significa que o servidor, considerando que sua renda futura era garantida, podia fazer um esforço de poupança menor durante sua vida ativa (MARQUES; MENDES, 
2004, p. 12). Dessa forma, considerando que o nível da remuneração dos servidores ativos não irá se alterar (mais baixo do que o do setor privado da economia), a mudança nas condições de aposentadorias será um desestímulo a que bons profissionais decidam fazer concurso público. Duas situações são possíveis para que isso não aconteça: a) um quadro de desemprego elevado, onde o Estado apareça como uma das únicas alternativas de ocupação; b) uma tendência à concentração da renda de ocupação nos níveis mais baixos.

Vista de outra perspectiva, a contra-reforma previdenciária do governo Lula constitui mais um passo no longo processo de destruição do Estado desenvolvimentista que vimos acontecer desde o governo Collor de forma explícita.

\subsection{A luta incessante por diminuir o orçamento SUS}

A luta do SUS por recursos já vem de longa data, podendo seu primeiro embate ser situado em 1993, quando $15,5 \%$ da arrecadação da contribuição de empregados e empregadores, previstos no orçamento da União, não foram repassados para o Ministério da Saúde (MS), obrigando-o a realizar um empréstimo junto ao Fundo de Amparo do Trabalhador (FAT) (MEDICI; SOARES; MARQUES, 1994). A isso se seguiram várias outras situações semelhantes, tornando incerto o orçamento da saúde pública.

Esperava-se que essa situação de incerteza fosse alterada pelo governo Lula, pois toda a agenda do SUS foi praticamente reproduzida na parte relativa à política de saúde do documento Programa de Governo 2002. Apesar das expectativas, o contrário ocorreu. $\mathrm{O}$ esforço em realizar um superávit primário superior ao acertado com o Fundo Monetário Internacional (FMI) implicou em constantes tentativas (vitoriosas ou não) de reduzir a disponibilidade de recursos para o orçamento da saúde pública.

Para que a natureza e a dimensão dos embates sejam compreendidas, faz-se necessário retomar, mesmo que de forma resumida, a trajetória da luta por garantia de recursos desenvolvida por aqueles comprometidos com o SUS e as dificuldades para a implementação dos acordos estabelecidos.

1.2.1 A garantia de recursos nas esferas federal, estadual e municipal e a definição de ações e serviços de saúde pública no período anterior a Lula

Em 1993, quando o MS deixou de receber os recursos previstos no orçamento da União, de origem nas contribuições de empregados e empregadores, os deputados Eduardo Jorge e Waldir Pires elaboraram a Proposta de Emenda Constitucional 169 (PEC 169) que, em resumo, vinculava recursos para a saúde.
Depois disso, várias outras propostas de vinculação foram elaboradas e discutidas no Congresso Nacional, mas somente em 2000 foi aprovada a Emenda Constitucional (EC 29). De acordo com a EC 29, a União deveria alocar, para o primeiro ano, pelo menos $5 \%$ a mais do que foi empenhado no orçamento do período anterior, e, para os seguintes, o valor apurado no ano anterior corrigido pela variação do PIB nominal. Para os estados e municípios, a EC 29 definia a alocação de pelo menos $7 \%$ de suas receitas de impostos, compreendidas as transferências constitucionais, para o primeiro ano, sendo que o percentual deveria aumentar anualmente até atingir, no mínimo, para os estados, $12 \%$, em 2004, e, para os municípios, $15 \%$.

Seguiu-se a isso todo um esforço no sentido de pactuar o conceito de ações e serviços de saúde, o que deveria agilizar a aplicação da EC 29. Entre as várias iniciativas destaca-se: a) a elaboração do documento Parâmetros consensuais sobre a implementação e regulamentação da EC 29, assinado pelo Conselho Nacional de Saúde (CNS) e várias outras entidades; b) a promoção, entre setembro de 2001 e setembro de 2002, por iniciativa do MS, de três seminários com os Tribunais de Contas da União, a comissão de Seguridade Social da Câmara e do Senado, o Conselho Nacional de Secretários de Saúde (CONASS) e o Conselho Nacional de Secretários Municipais de Saúde (CONASEMS). Esses seminários tinham a finalidade de buscar uma interpretação homogênea e assegurar os objetivos que motivaram a aprovação da emenda; c) a Resolução 322 de 2003 do CNS, homologada pelo Ministro da Saúde em 8 de maio desse ano, onde são definidos as ações e os serviços de saúde pública; d) a elaboração do Projeto de Lei Complementar 01/2003, que começou a tramitar na Câmara Federal em 2004.

Após intensos debates entre o Governo Federal (contrário à vinculação de recursos, entre outros aspectos) e a Frente Parlamentar da Saúde, o projeto foi aprovado nas três Comissões da Câmara: a Comissão de Seguridade Social e Família; a Comissão de Finanças e Tributação da Câmara; e a Comissão de Constituição e Justiça. Ainda, após inúmeras tentativas e pressões das entidades ligadas ao Movimento da Reforma Sanitária, o PLC 01/2003 encontra-se, no momento, dentre os projetos que fazem parte da pauta de votação no plenário da Câmara. Contudo, o tempo para isso é ainda incerto, principalmente em ano de eleição do executivo, em que quase tudo fica para ser votado no ano seguinte.

\subsubsection{Os recursos do SUS no governo Lula}

No primeiro ano do mandato de Lula (2003), durante as negociações de sua proposta de reforma tributária, representantes do governo defenderam a aplicação de mecanismos semelhantes à Desvinculação das Receitas da União (DRU) para 
os estados e municípios, o que, segundo estimativa da Comissão de Orçamento e Finanças do CNS, implicaria uma redução de recursos para a saúde de $\mathrm{R} \$ 3$ bilhões em nível dos estados e de R $\$ 2,5$ bilhões em nível dos municípios, caso a desvinculação de $20 \%$ fosse aplicada à arrecadação prevista para 2003 (MARQUES; MENDES, 2005). Frente à oposição manifestada, essa proposta foi retirada do âmbito do projeto do executivo.

Mas é importante que se diga que essa proposta fazia (e faz) parte de uma estratégia mais ampla, pois ao final de 2003, o Governo Federal encaminhou documento referente ao novo acordo com o FMI, comunicando sua intenção em preparar um estudo sobre as implicações das vinculações constitucionais das despesas sociais - saúde e educação sobre as receitas dos orçamentos da União, dos estados ou dos municípios. A justificativa apoiava-se na idéia de que a flexibilização da alocação dos recursos públicos poderia assegurar uma trajetória de crescimento ao país (BRASIL, 2004). No âmbito do SUS, a intenção do governo era tirar do Ministério da Saúde a obrigação de gastar, em relação ao ano anterior, valor igual acrescido da variação nominal do PIB; dos estados, $12 \%$ de sua receita de impostos, compreendidas as transferências constitucionais; e, dos municípios, $15 \%$, tal como define a EC 29.

Uma segunda investida do governo Lula contra a saúde manifestou-se no descumprimento da Proposta Orçamentária 2004 do MS. Em 31 de julho de 2003, a Saúde foi surpreendida com o veto presidencial ao parágrafo 2 , do artigo 59 da Lei das Diretrizes Orçamentária (LDO) 2004. Por meio deste ato, seriam consideradas como ações e serviços públicos de saúde as despesas realizadas com Encargos Previdenciários da União (EPU) e com o serviço da dívida, bem como a dotação dos recursos do Fundo de Combate e Erradicação da Pobreza. A reação contrária do CNS e da Frente Parlamentar da Saúde resultou na mensagem do Poder Executivo ao Congresso Nacional criando o parágrafo 3 para o artigo 59, onde, para efeito das ações em saúde, são deduzidos os EPU e o serviço da dívida. Contudo, nenhuma menção foi feita ao Fundo de Combate e Erradicação da Pobreza, com recursos previstos atingindo $\mathrm{R} \$ 3,57$ bilhões, cujas atividades não são consideradas típicas da saúde pública.

Mas além dos efeitos negativos dessa redução ao orçamento do MS, o descumprimento da EC 29 pela União abriria precedente para que os estados atuassem da mesma forma, isto é: considerar como despesas em saúde outros itens que não se referem a 'ações típicas de saúde'. E é o que aconteceu em setembro de 2003, quando a governadora do estado do Rio de Janeiro propôs ao Supremo Tribunal Federal uma Ação Direta de Inconstitucionalidade (ADIN) com pedido de medida cautelar, em razão da Resolução 322/2003 do CNS, especialmente para sua invalidação e suspensão imediata dos seus efeitos. A governadora questionava particularmente a diretriz da Resolução que define as despesas a serem consideradas como ações e serviços públicos de saúde, com o intuito de incluir gastos na saúde que são por ela vedados. Além desse questionamento, a ADIN indaga sobre o caráter deliberativo do CNS para determinar as formas de aplicação do gasto com ações e serviços públicos de saúde.

A negociação realizada para a superação do impasse entre a institucionalização do SUS e a austeridade fiscal preconizada pela equipe econômica resultou, finalmente, na reintrodução do conteúdo do parágrafo 2 do artigo 59 da LDO 2004 na Lei ${ }^{\circ} 10.777$ de 25 de novembro de 2003. Dessa forma ficou assegurado que os encargos previdenciários da União, os serviços da dívida e a parcela das despesas do Ministério financiada com recursos do Fundo de Combate e Erradicação da Pobreza não seriam considerados como ações e serviços públicos de saúde. Esse resultado somente foi possível mediante parecer da Procuradoria Geral da União.

Em 2005, quando do encaminhamento da LDO 2006 ao Legislativo, novamente se manifestou a mesma desconsideração do governo Lula com relação ao conceito de saúde, construído sob o consenso das entidades do setor. No projeto encaminhado, as despesas com assistência médica hospitalar dos militares e seus dependentes (sistema fechado) seriam consideradas no cálculo de ações e serviços de saúde, o que diminuiria em R $\$ 500$ milhões o orçamento do MS. Depois do repúdio público do Conselho Nacional de Saúde, esse item deixou de ser considerado gasto SUS. 


\section{Resgatando a miséria e nivelando por baixo}

\subsection{O Bolsa Família}

Segundo o próprio governo, o carro-chefe de sua política social é o Bolsa Família, programa de transferência de renda para as famílias situadas abaixo da linha de pobreza. Esse programa, ainda no dizer oficial, foi criado para combater a miséria e a exclusão social e para promover a emancipação das famílias mais pobres. Essa iniciativa, fruto da unificação de diversos programas pré-existentes, tais como o Bolsa Escola, Bolsa Alimentação, Cartão Alimentação e o Auxílio Gás (cada um deles sob a tutela de um Ministério diferente na gestão FHC), foi mais além do que sua simples unificação e centralização sob um mesmo Ministério, o do Desenvolvimento Social e Combate à Fome (MDS). Essa ampliação é patente, tanto em relação à sua cobertura quanto em relação ao benefício concedido. Em maio de 2006, o programa estava implantado em $99,9 \%$ dos municípios brasileiros, beneficiando 11,118 milhões de famílias, atingindo, portanto, quase 47 milhões de brasileiros. Em relação ao valor do benefício, diferenciou-se dos benefícios concedidos anteriormente por introduzir uma parte fixa, não relacionada à existência de filhos em idade escolar, o que, sem dúvida, foi um avanço, não permitindo se dizer que se trata de simples continuação de um programa já existente. Os critérios de acesso e os benefícios podem ser vistos no Quadro 1. Vale lembrar que as famílias beneficiadas, com filhos entre zero e 15 anos de idade devem, como contrapartida, matricular e garantir a freqüência de seus filhos na escola, cumprir o calendário de vacinações, fazer o acompanhamento pré-natal e participar de ações educativas sobre aleitamento materno e alimentação saudável.

Não há como discordar sobre a importância desse programa para as famílias beneficiadas e para os municípios onde elas habitam. Diferentes pesquisas indicam que: a) em média, o benefício representa $21 \%$ do orçamento familiar; b) em vários municípios brasileiros, os recursos recebidos constituem a principal fonte de renda, superando enormemente não só a arrecadação municipal como as transferências constitucionais, os recursos destinados à saúde pública, entre outros indicadores. Há municípios em que quase a metade da população é beneficiada por esse programa (MARQUES et al., 2004). Todas as pesquisas apontam que as famílias destinam os recursos para a compra de alimentos, animando o mercado local.

Apesar do avanço que significa a cobertura do Bolsa Família, vários são os problemas a ele associados. O primeiro deles diz respeito ao fato de ser um programa, não derivando disso um direito para a família beneficiária. Como diz Yazbek (2004, p. 112):

Essa disputa apresenta um grande risco: que o Programa permaneça apenas no plano do assistencialismo e do dever moral e humanitário de prestar socorro aos pobres, não se realizando como direito social (e assim não se politizando). É evidente que uma 'cruzada solidária' contra a fome tem grande apelo e é capaz de realizar um consenso social (dimensão importante para o governo), mas é também mais do que conhecida a necessidade de enfrentar, no âmbito estrutural das relações sociais, as causas da fome e da pobreza.

Não se constituindo um direito, sua continuidade fica ao sabor da prioridade do presidente de plantão. O segundo aspecto criticável do programa é a condição mínima de acesso, pois somente são beneficiadas as famílias que apresentarem uma renda per capita inferior a R\$ 60. Supondo que o per capita familiar seja exatamente igual ao limite superior do critério de acesso, o benefício de $\mathrm{R} \$ 50$ totalizaria uma renda de R\$ 290 (considerada uma família de quatro membros), bem abaixo do salário mínimo de R \$ 350 (vigente desde abril de 2006). Isso significa que na definição dessa política não está sendo considerado sequer o parâmetro salário mínimo.

Quadro 1 - Bolsa Família e seu benefício - 2006

\begin{tabular}{|c|c|c|c|c|}
\hline \multicolumn{2}{|c|}{ Critério de Elegibilidade } & \multirow{2}{*}{$\begin{array}{c}\text { Ocorrência de crianças / } \\
\text { Adolescentes } 0-15 \text { anos, } \\
\text { Gestantes e Nutrizes }\end{array}$} & \multirow{2}{*}{$\begin{array}{l}\text { Quantidade e } \\
\text { Tipo de } \\
\text { Benefícios }\end{array}$} & \multirow[b]{2}{*}{$\begin{array}{c}\text { Valores } \\
\mathrm{R} \$\end{array}$} \\
\hline $\begin{array}{l}\text { Situação das } \\
\text { Famílias }\end{array}$ & $\begin{array}{c}\text { Renda } \\
\text { Mensal Per Capita }\end{array}$ & & & \\
\hline Situação de Pobreza & $\begin{array}{c}\text { De } R \$ 60,01 \\
a \\
R \$ 120\end{array}$ & $\begin{array}{l}1 \text { Membro } \\
2 \text { Membros } \\
3 \text { ou }+ \text { Membros }\end{array}$ & $\begin{array}{l}\text { (1) Variável } \\
\text { (2) Variável } \\
\text { (3) Variável }\end{array}$ & $\begin{array}{l}15 \\
30 \\
45\end{array}$ \\
\hline $\begin{array}{c}\text { Situação de Extrema } \\
\text { Pobreza }\end{array}$ & $\begin{array}{c}\text { Até } \\
\mathrm{R} \$ 60\end{array}$ & $\begin{array}{l}\text { Sem ocorrência } \\
1 \text { Membro } \\
2 \text { Membros } \\
3 \text { ou + Membros }\end{array}$ & $\begin{array}{l}\text { Básico } \\
\text { Básico + (1) Variável } \\
\text { Básico + (2) Variável } \\
\text { Básico + (3) Variável }\end{array}$ & $\begin{array}{l}50 \\
65 \\
80 \\
95\end{array}$ \\
\hline
\end{tabular}

Fonte: Ministério do Desenvolvimento Social e Combate à Fome: <www.mds.gov.br>. 
Mesmo levando em conta que o salário mínimo perdeu seu sentido primeiro de constituir um piso salarial legal, abaixo do qual qualquer pagamento seria considerado imoral pela sociedade, capaz de prover a manutenção do trabalhador e sua família, o fato do Bolsa Família não tê-lo como referencial implica que o governo Lula não considera o direito de todos poderem contar com igual renda mínima, no caso, de valor igual ao salário mínimo, mesmo que seu valor real tenha de deteriorado ao longo do tempo. O entendimento de que o salário mínimo deva corresponder à renda mínima necessária para a sobrevivência decorre do óbvio: de não haver diferença entre as necessidades básicas de um assalariado e de um catador de caranguejos, por exemplo.

Já não é esse o tratamento no momento da concessão do Benefício de Prestação Continuada (BPC) - instituído constitucionalmente, dirigido a portadores de deficiência e a idosos de baixa renda. Neste caso, além da defíciência e da idade, o critério de acesso é pertencer à família com renda per capita inferior a $25 \%$ do salário mínimo. Talvez a diferença entre as condições de acesso ao Bolsa Família e ao BPC (idosos) seja explicada pelo fato de esse último, que se constitui em direito, estar fundamentado na idéia do trabalho, tratando-se de um valor de base dirigido a quem se retirou do mercado de trabalho, isto é, corresponde à cobertura do risco velhice. No caso dos beneficiários do Bolsa Família, embora pareça que não, a idéia do trabalho também está presente, pois pressupõe que a família busque trabalho para completar sua renda. Mas as condições em que essa busca ocorre são as mesmas de antes, pois as determinações das rendas e do emprego nos grotões do país e mesmo na periferia das grandes capitais não sofreram nenhuma alteração para melhor.

A história da acumulação brasileira indica que faz parte de sua dinâmica uma lógica perversa, de forma que, seja qual for o desempenho da economia, a desigualdade aumenta e, com ela o tamanho da pobreza. Em outras palavras, o último problema relativo ao Bolsa Família reside no fato de o governo Lula não ter alterado os determinantes da pobreza estrutural brasileira. E, mesmo que tivesse levado adiante políticas que alterassem essa lógica, algumas delas teriam impacto no médio e no longo prazo, o que justificaria tratar a renda concedida pelo Bolsa Família como um direito e não como algo dependente de um programa, passível de ser extinto sem que a sociedade brasileira participe dessa decisão.

\subsection{Salário mínimo e renda da ocupação}

Enquanto candidato à presidência da República, Luiz Inácio Lula da Silva falava em dobrar o valor do salário mínimo. Já no Programa de Governo 2002 (2006, p. 31), afirmava: "[...] nosso governo trabalhará com um programa de reajuste progressivo do poder de compra do salário mínimo". Ao final, entre dezembro de 2002 e setembro de 2006, o salário mínimo real aumentou $40 \%$, beneficiando os trabalhadores de mais baixa renda e os beneficiários do piso previdenciário (principalmente rurais) e do BPC.

Contudo, a evolução do rendimento dos ocupados não acompanhou essa melhora do salário mínimo, muito pelo contrário. O mau desempenho econômico registrado no primeiro ano do governo Lula (2003) provocou redução de $12,6 \%$ do rendimento médio habitual $^{1}$ real do trabalhador brasileiro em relação a 2002. Essa redução foi observada em todas as categorias de ocupação, apesar daquelas mais organizadas terem firmado acordos de reajuste salarial favoráveis no segundo semestre, quando o nível de atividade se recuperou um pouco. Ao mesmo tempo, a taxa média de desemprego aberto das cinco regiões metropolitanas, calculada pelo Instituto Brasileiro de Geografia e Estatística (IBGE), registrou aumento (12,3\%; quando era $11,7 \%$ em 2002). Em 2004, muito embora a economia tenha crescido $4,9 \%$, o rendimento médio real dos ocupados recuou mais $0,7 \%$, mas a taxa média de desemprego no ano caiu para $11,5 \%$. Em 2005, o rendimento médio habitual real apresentou uma pequena recuperação, crescendo $2 \%$ em relação ao ano anterior. Mas esse desempenho não atingiu os trabalhadores com carteira assinada, os quais sofreram redução de $0,8 \%$ em seu rendimento médio habitual real (em 2004 ele havia aumentado 0,3\% e, em 2003, havia se reduzido em 4,9\%). Nesse ano, a taxa média de desemprego continuou a cair, registrando $9,8 \%$.

Os três primeiros anos do governo Lula caracterizaram-se, portanto, pela redução do rendimento médio real habitual dos ocupados. Ao mesmo tempo, continuou o processo, em governos anteriores já observado, de concentração dos ocupados nas faixas de renda mais baixas. Em 2004, 89,9\% dos ocupados com dez anos ou mais recebiam, a título de rendimento principal, até cinco salários mínimos. Em 2002, esse percentual era de 87,6\% (IBGE, 2006).

Para se ter idéia da importância do mercado informal no total dos ocupados, em 2004, segundo a Pesquisa Nacional de Amostra por Domicílios 
(PNAD), realizada pelo IBGE (PNAD, 2004), $53,45 \%$ dos ocupados com 10 anos ou mais não contribuíam para qualquer instituto de previdência.

Há ainda um outro aspecto do governo Lula que merece destaque: de como correspondeu à sua promessa de campanha de criar 10 milhões de novos empregos. De acordo com o Cadastro Geral de Empregados e Desempregados (Caged), do Ministério do Trabalho e do Emprego, nos três primeiros anos do governo Lula, foram criados 3.422 .700 empregos formais (admissões líquidas $=$ contratação - desligamento), isto é, com carteira assinada, significando que os trabalhadores estão amparados pelas leis trabalhistas e previdenciárias vigentes. O resultado anunciado ficou, portanto, bastante aquém de sua promessa. E tal constatação é válida mesmo considerando a continuação da expansão do emprego informal durante esse período. O que permite dizer que, além daqueles empregos, foram gerados outros 3.922.149 (mantida a participação, de 2004, dos ocupados que não contribuem para nenhum instituto de previdência), totalizando 7.344 .849 novas ocupações.

De qualquer forma, esse resultado, além de estar longe do prometido durante a campanha eleitoral de Lula, estaria fundado na permanência do domínio do trabalho informal no mercado.

\section{Conclusão}

Do exposto, concluiu-se que não há impedimento entre o desenvolvimento da política econômica do governo Lula, voltada para o grande capital, em particular o financeiro, e a realização de programas direcionados às parcelas mais pobres da população, tal como o Bolsa Família.

O programa de transferência de renda desenvolvido pelo governo Lula de fato alterou as condições de existência das famílias beneficiadas, retirando-as da pobreza absoluta. Contudo, ao não estar associado a mudanças estruturais, pois os determinantes da pobreza não foram alterados, não impede que novos contingentes nessa situação surjam e nem que essas famílias possam, no médio e longo prazo, viverem sem esses recursos.

Apesar de o Bolsa Família não constituir um direito, sendo um benefício decorrente de um programa governamental, a rigor não pode ser comparado com as tradicionais políticas assistencialistas, voltadas para segmentos excluídos 'minoritários' que, no falar da literatura, estavam à margem da dinâmica da sociedade. Um novo conceito precisa ser elaborado para a realidade brasileira, pois quase $50 \mathrm{mi}$ lhões de brasileiros não podem ser considerados uma 'minoria' e nem é possível se defender que estejam à margem da acumulação capitalista brasileira. Esses, junto com outros trabalhadores em melhor situação, compõem o exército industrial de reserva, como disse Marx em O Capital, pressionando para baixo a remuneração dos assalariados e possibilitando as péssimas condições de trabalho e de existência da maioria do povo brasileiro. Mas, na medida em que o governo não faz do Bolsa Família um direito, ganha força o entendimento que se trata de uma mera política assistencial. Mas assistencial no sentido vivido historicamente pelo povo brasileiro, de algo que um governo concede, porque assim quer. Contudo, no lugar de chamar o Bolsa Família de assistencial, melhor seria transformá-lo em renda mínima, a que toda família deveria ter direito.

Essa alternativa, no entanto, entraria em contradição com a política mais geral do governo Lula na esfera social. Essa, embora não explícita, encaminha-se para transformar a proteção social garantida pelo Estado em uma proteção de mínimos, o que fica evidente quando da insistência nos fundos de pensão (para os trabalhadores do setor privado e para os funcionários públicos), na preocupação em desvincular os recursos da Seguridade Social e nas constantes tentativas de redução do orçamento do SUS. A garantia de uma renda familiar mínima, financiada com recursos de impostos, colocaria em questão a definição dos mínimos.

Também essa alternativa evidenciaria quão perversa está sendo a evolução da renda da ocupação, que está se concentrando nas faixas de rendimentos mais baixas. Isso porque a garantia de uma renda mínima familiar aproximaria seus beneficiários dos demais trabalhadores, fazendo com que esses últimos se sentissem ainda mais empobrecidos, distantes dos segmentos mais ricos da população brasileira. Mas, continuando o Bolsa Família a ser um programa, mantémse o governo longe desse problema. Coisa que a sociedade brasileira não tem como evitar, a continuar a evolução da distribuição do rendimento da ocupação.

\section{Referências}

BRASIL. Ministério da Fazenda. Carta de intenção referente ao novo acordo com o FMI, 2003. Disponível em <http:// www.fazenda.gov.br>. Acesso em: 30 set. 2006.

DE PAULA, J. A. (Org.) Adeus ao desenvolvimento: a opção do governo Lula. Belo Horizonte: Editora Autêntica, 2005.

EMI. Exposição de Motivos Interministerial I do projeto de reforma previdenciária n. 29-MPS/C.CIVIL-PR, Brasília, 29 de abril de 2003.

IBGE - Instituto Brasileiro de Geografia e Estatística. SIDRA - Sistema IBGE de Recuperação Automática. Disponível em $<$ http://www.sidra.ibge.gov.br/bda/default.asp? $\mathrm{z}=\mathrm{t} \& \mathrm{o}$ $=1 \& \mathrm{i}=\mathrm{P}>$. Acesso em: dez. 2006. 
MARQUES, R. M. A proteção social e o mundo do trabalho. São Paulo: Bienal, 1997.

MARQUES, R. M.; MENDES, Á. O governo Lula e a contra-reforma previdenciária. São Paulo em Perspectiva, São Paulo, v. 18, n. 3, p. 3-15, 2004.

. SUS e Seguridade Social: em busca do elo perdido. Saúde e Sociedade, São Paulo, v. 14, n. 2, p. 39-49, maio-ago. 2005.

MARQUES, R. M. et al. A Importância do Bolsa Família nos municípios brasileiros, Relatório de pesquisa. MINISTÉRIO DO DESENVOLVIMENTO SOCIAL E COMBATE À FOME - MDS, Brasília, 2004. Disponível em http://www.mds.gov.br/institucional/secretarias/secretariade-avaliacao-e-gestao-da-informacao-sagi/estudos-epesquisas/cadernos_de_estudos. Acesso em: dez 2006.

MARQUES, R. M.; NAKATANI, P. A Política econômica do governo Lula: como mudar para ficar no mesmo. Revista Tiers Monde, Paris. No prelo.

MEDICI, A; SOARES, L.; MARQUES, R. M. Saúde no contexto da seguridade: dilemas de financiamento. Revista Saúde e Debate, Rio de Janeiro, n. 44, p. 55-68, set. 1994.

OLIVEIRA, F. O Ornitorrinco. In: Crítica à razão dualista e o ornitorrinco. S. Paulo: Boitempo, 2003. p. 121-150.

PNAD-Pesquisa Nacional por Amostra de Domicílio 2004. Disponível em <www.ibge.gov.br/home/estatistica/ populacao/trabalhoerendimento/pnad2004>. Acesso em: dez. 2006.

PROGRAMA DE GOVERNO 2002. Reforma da Previdência. Disponível em <http://www.pt.org.br/site/assets/ programadegoverno.pdf>. Acesso em: dez. 2006

YAZBEK, M. C. O Programa Fome Zero no contexto das políticas sociais brasileiras. São Paulo em Perspectiva, São Paulo, v. 18, n. 2, p. 104-112, 2004.

\section{Nota}

1 No cálculo do rendimento habitual não são considerados as horas extras, os atrasados, as férias, etc.

\section{Rosa Maria Marques}

Doutora em Economia pela Fundação Getúlio Vargas Professora no Departamento de Economia e no Programa de Estudos Pós-Graduados em Economia Política da PUCSP
Rua Cayowáa, 560, apt. 112, Perdizes

São Paulo - São Paulo

CEP: 05018-000

\section{Áquilas Mendes}

Doutor em Economia pela Universidade Estadual de Campinas (UNICAMP)

Vice-presidente da Associação Brasileira de Economia da Saúde (ABRES)

Professor no Departamento de Economia da PUCSP e na Faculdade de Economia da FAAP/SP

Rua Alagoas, 903

Higienópolis

São Paulo - SP

CEP: 01242-902 